\title{
基于氧化铇和氧化镍的电致变色器件研究进展
}

\author{
钟晓岗 ${ }^{1}$, 刘雪晴 ${ }^{1}$, 刀训刚 ${ }^{2}$ \\ (北京航空航天大学 1. 物理学院; 2. 能源与动力工程学院, 北京 100191)
}

摘 要: 电致变色器件(Electrochromic Devices, ECDs)是一种颜色变化受电压调控的智能装置, 具有工作温度范围宽、 光学对比度高、可逆双稳态性能好、驱动电压低和能耗低等优点, 在智能动态调光窗、全彩色电子显示屏、防眩光护 目镜、自适应双隐身伪装以及可视化储能等领域展现出了巨大的应用潜力。阴极着色材料氧化铇 $\left(\mathrm{WO}_{3}\right)$ 和阳极着色材 料氧化镍 $(\mathrm{NiO})$ 是两种被广泛研究的无机电致变色材料, 由 $\mathrm{WO}_{3}$ 和 $\mathrm{NiO}$ 薄膜组成的互补型电致变色器件在大规模智能 窗的应用中具有极高的商业价值。改善电致变色器件的综合性能如光学调制范围、响应速度、循环寿命和耐候性等 问题一直备受关注。本文围绕互补型电致变色器件的结构组成, 综述了基于 $\mathrm{WO}_{3}$ 和 $\mathrm{NiO}$ 的电致变色全器件的近期研 究进展。首先分别阐述了 $\mathrm{WO}_{3}$ 和 $\mathrm{NiO}$ 薄膜的电致变色机理和衰退机制, 讨论了改进制备工艺、元素掺杂改性、设计 纳米结构和引入复合材料这四种薄膜性能优化策略的作用和最新研究进展, 其次, 按照器件的组成成分和结构设计 介绍了互补型电致变色全器件的分类体系, 总结了各组分材料的选择和器件结构对器件综合性能的影响, 最后对电 致变色器件的应用前景和发展趋势进行了展望。

关 键 词: 电致变色器件; 氧化铇; 氧化镍; 综述

中图分类号: O439; O484 文献标识码: A

\section{Electrochromic Devices Based on Tungsten Oxide and Nickel Oxide: a Review}

\author{
ZHONG Xiaolan ${ }^{1}$, LIU Xueqing ${ }^{1}$, DIAO Xungang ${ }^{2}$
}

(1. School of Physics, Beihang University, Beijing 100191, China; 2. School of Energy and Power Engineering, Beihang University, Beijing 100191, China)

Abstract: Electrochromic devices (ECDs) are the intelligent devices change color by applying electric potential, with the advantages of wide working temperature, high optical contrast, good reversible bistability, low driving voltage, and low energy consumption, which show great application potential in the field of dynamic smart windows, full-color electronic screens, anti-glare goggles, adaptive dual-stealth camouflage, and energy storage status visualization. Cathodically coloring material tungsten oxide and anodically coloring material nickel oxide are two widely studied inorganic electrochromic materials, and complementary electrochromic devices based on $\mathrm{WO}_{3}$ and $\mathrm{NiO}$ films have high commercial values in the application of large scale smart windows. Improving the performance of the complementary ECDs such as optical modulation range, response rate, cycle life and weather fastness has attracted much attention. This review focuses on the structural composition of complementary electrochromic devices and

收稿日期: 2020-08-24; 收到修改稿日期：2020-09-23; 网络出版日期: 2020-11-05

基金项目: 国家自然科学基金(61875005, 11804018) National Natural Science Foundation of China $(61875005,11804018)$

作者简介: 钟晓岗(1986-), 女, 副教授. Email: zhongxl@buaa.edu.cn ZHONG Xiaolan(1986-), female, associate professor. E-mail: zhongxl@buaa.edu.cn

通信作者: フ训刚，教授. E-mail: diaoxg@buaa.edu.cn DIAO Xungang, professor. E-mail: diaoxg@buaa.edu.cn 
summarizes the recent research progress of the electrochromic full devices based on $\mathrm{WO}_{3}$ and NiO. Firstly, the electrochromic mechanism and decay mechanism of $\mathrm{WO}_{3}$ and $\mathrm{NiO}$ films are clarified, the effects and latest research progress of four strategies for film performance optimization that include optimizing preparation conditions, element doping modification, designing nanostructure, and introducing composite materials are discussed in detail. Secondly, according to the composition and structure design of the device, the classification system of the complementary electrochromic full device is introduced, and the influence of selection for each component material and the device structure on device overall performance are summarized. Finally, the application of the electrochromic device prospects and development trends are forecasted.

Key words: electrochromic device; tungsten oxide; nickel oxide; review

电致变色(Electrochromic, EC)是指材料的光学 特性如透过率、反射率、发射率等在外电场的控制 下发生稳定、可逆变化的一种智能调控技术，断压 后的电致变色器件仍能在着色和褪色两种状态之间 保持稳定，这种仅需在变色的一瞬间施加电压的低 能耗性使其在节能建筑中具有独一无二的优势, 尤其 是在办公大楼的智能窗和客机眩窗等领域应用广泛。

自 1969 年 Deb 研制出第一个基于 $\mathrm{WO}_{3}$ 的电致 变色器件以来 ${ }^{[1]}$, 提高电致变色器件性能的研究就 一直是人们关注的重点。目前大多数的电致变色器 件仍存在颜色或透过率调制范围小、响应速度慢、 循环稳定性差、装配工艺不完善和难以大规模制备 等种种问题，而发挥阴极和阳极电致变色材料协同 补色作用的互补型器件在提高光学对比度和循环寿 命等方面的作用已得到普遍认可, 并大规模运用在 智能窗的商业化生产中。阴极电致变色材料是指在 发生还原反应时着色的一种无机过渡金属氧化物 ${ }^{[2-3]}$, 包括 $\mathrm{WO}_{3} 、 \mathrm{TiO}_{2} 、 \mathrm{Ta}_{2} \mathrm{O}_{5}$ 等 ${ }^{[4]}$, 其中 $\mathrm{WO}_{3}$ 作为最早 被深入研究的电致变色材料, 其变色机理相对清晰, 制备工艺也日趋成熟, 常用作互补型电致变色器件 中的关键变色层。有多种适合与 $\mathrm{WO}_{3}$ 组成互补型器 件的阳极电致变色材料, 如 $\mathrm{IrO}_{2}{ }^{[5]} 、 \mathrm{~V}_{2} \mathrm{O}_{5}{ }^{[6]}$ 和 $\mathrm{NiO}^{[7]}$ 等, 其中 $\mathrm{NiO}$ 是最具前途的一种阳极电致变色材料, 具有光学调制范围大、着色效率高和循环耐久性好 等诸多优点, 在互补型电致变色器件中常被用作 $\mathrm{WO}_{3}$ 的对电极。

本文综述了基于 $\mathrm{WO}_{3}$ 和 $\mathrm{NiO}$ 的电致变色器件 的最新研究进展, 介绍了 $\mathrm{WO}_{3}$ 和 $\mathrm{NiO}$ 两种典型电致 变色薄膜的变色机理、衰退机制和制备工艺，重点 讨论了提高 $\mathrm{WO}_{3}$ 和 $\mathrm{NiO}$ 薄膜性能的几种有效策略, 随后介绍了透明导电层和离子传导层的材料分类和 传统与新型的器件结构设计, 并总结了各层薄膜性 质和器件组装方式对全器件性能的影响, 最后展望了 互补型电致变色器件的应用前景和未来研究趋势。

\section{$1 \mathrm{WO}_{3}$ 薄膜研究进展}

\section{$1.1 \mathrm{WO}_{3}$ 的结构和变色机理}

氧化铇是最早被研究的一种阴极电致变色材料, 可分为结晶态 $\mathrm{WO}_{3}$ 和非晶态 $\mathrm{WO}_{3}$ 。 晶体 $\mathrm{WO}_{3}$ 由周 期性排列的 $\mathrm{WO}_{6}$ 正八面体组成, 是一种类钙钣矿结 构, $\mathrm{W}$ 原子位于八面体的中心, $\mathrm{O}$ 原子作为连接点使 $\mathrm{WO}_{3}$ 内部形成可供离子传输的多边形通道。非晶态 $\mathrm{WO}_{3}$ 由于相对无序的结构提供了更大的离子通道 和更多的反应位点, 往往表现出优异的 EC 性能, 但 稳定性通常不如晶体 $\mathrm{WO}_{3}$ 。

对 $\mathrm{WO}_{3}$ 电致变色机理的研究可追溯到 1973 年 Deb 提出的色心模型 ${ }^{[8]}$, 非晶 $\mathrm{WO}_{3}$ 中的氧空位缺陷 带正电荷, 能俘获电子形成 $\mathrm{F}$ 色心, 色心不稳定吸 收光子产生激发态, 从而导致 $\mathrm{WO}_{3}$ 着色, 但是色心 模型无法解释晶体 $\mathrm{WO}_{3}$ 的变色。1975 年, Faughnan 提出了价间跃迁模型 ${ }^{[9]}$, 又称为双注入模型, 当离 子和电子同时注入到 $\mathrm{WO}_{3}$ 薄膜时, $\mathrm{WO}_{3}$ 发生可逆的 氧化还原反应，如式(1):

$$
\mathrm{WO}_{3} \text { (bleached) }+x \mathrm{M}^{+}+x \mathrm{e}^{-} \leftrightarrow \mathrm{M}_{x} \mathrm{WO}_{3} \text { (colored) }
$$

其中， $\mathrm{M}^{+}$表示 $\mathrm{H}^{+} 、 \mathrm{Li}^{+} 、 \mathrm{Na}^{+} 、 \mathrm{~K}^{+}$等阳离子，电荷在 $\mathrm{W}^{6+}$ 和 $\mathrm{W}^{5+}$ 之间转移引起 $\mathrm{WO}_{3}$ 光吸收的变化, 薄膜 从透明变成蓝色。Schirmer 等 ${ }^{[10]}$ 提出的小极化子模 型也是基于离子和电子共同注入和抽出的观点，除 此之外还有能级模型、配位场模型等理论, 这些变 色理论都有各自的局限性，但离子和电子共同作用 的电致变色机理目前已得到普遍认可。

\section{$1.2 \mathrm{WO}_{3}$ 薄膜的衰退机制}

$\mathrm{WO}_{3}$ 电致变色薄膜具有大光学调制范围、高着 色效率、良好的可逆性等诸多优点，相比于有机电 致变色材料, $\mathrm{WO}_{3}$ 薄膜还能在多次循环过程中保持 稳定、可逆的颜色变化, 以及在恶劣的环境中持续 
地工作。然而, 在长时间的电荷插入和抽出的过程 中, $\mathrm{WO}_{3}$ 薄膜和器件的 $\mathrm{EC}$ 性能会大幅度下降, 如光 调制能力减弱、响应时间变长等, 严重影响了电致 变色器件的实际使用效果。

目前对 $\mathrm{WO}_{3}$ 薄膜和器件退化机制的研究很少, 通常认为薄膜和器件性能的下降是由于宿主结构中 捕获离子的积累。北京工业大学严辉课题组 ${ }^{[11]}$ 将 $\mathrm{WO}_{3}$ 膜的降解过程分为漂白态和着色态的衰退。如 图 1 所示, 着色过程中插入离子电荷密度的降低是 导致着色态退化的主要原因, 捕获离子的积累还会 造成两电极间开路电位 $(\mathrm{OCP})$ 的衰减, 减弱了驱动 离子进入薄膜的电场力。该课题组还研究了插入离 子数与 $\mathrm{WO}_{3}$ 薄膜 $\mathrm{EC}$ 性能和退化情况的关系 ${ }^{[12]}$, 大 量的离子插入虽然在一定程度上提高了薄膜的光调 制能力, 但会严重破坏薄膜结构, 已被捕获的离子 难以被提取出来, 最终导致 $\mathrm{WO}_{3}$ 薄膜的快速衰退。

\section{$1.3 \mathrm{WO}_{3}$ 薄膜的性能优化}

无机电致变色材料 $\mathrm{WO}_{3}$ 具有从透明态到深蓝 色变化的大透过率调制范围和柔和舒适的颜色转换, 在智能窗的生产和应用中具有不可比拟的优势, 能 够调节窗口的透过照明强度以提供舒适的室内环 境、美学设计和提高建筑节能效率。然而, $\mathrm{WO}_{3}$ 薄
膜的致密性和较低的扩散系数使其切换时间非常长, 在需要快速响应的电子设备等领域表现得不尽人意, 提高 $\mathrm{WO}_{3}$ 的响应速度、着色效率仍是当前研究的重 点, 改进制备方法、掺杂元素、设计纳米结构和复 合材料是改善 $\mathrm{WO}_{3}$ 薄膜性能的几种常用手段。

\subsection{1 制备方法}

常用的 $\mathrm{WO}_{3}$ 薄膜生产方法有水热法 ${ }^{[13]}$ 、溶剂热 法 $^{[14]}$ 、溶胶-凝胶法 ${ }^{[15]}$ 、电化学沉积法 ${ }^{[16]}$ 、喷墨打 $\mathrm{E}^{[17]}$ 和磁控溅射法 ${ }^{[18]}$ 等。由于 $\mathrm{WO}_{3}$ 薄膜的制备方 法多样, 每种方法的可调参数较多, 所以在不同工 艺下制备的 $\mathrm{WO}_{3}$ 薄膜质量差异很大。水热法是一种 高温高压控制晶体生长的方法, 但需要先在基底上 制备晶种层, 电子科技大学贾春阳等 ${ }^{[13]}$ 研究了一种 简单高效制备 $\mathrm{WO}_{3}$ 薄膜的一步水热法, 使用甘油作 为自种剂, 无需预先制备晶种层, 制备出的 $\mathrm{WO}_{3}$ 薄 膜具有 15000 次的高循环稳定性和 $78.1 \%$ 的大光学 调制幅度, 着褪色时间较短 $(5 \mathrm{~s} / 6 \mathrm{~s})$ 。河南大学蔡国 发等 ${ }^{[16]}$ 采用了一种新颖的脉冲电化学沉积法制备 高性能的多孔 $\mathrm{WO}_{3}$ 薄膜, 这种方法无需模板和热处 理, 适用于不同的导电基底, 其中在 ITO 玻璃上制 备的 $\mathrm{WO}_{3}$ 薄膜具有 $97.7 \%$ 超大光学调制幅度和 $118.3 \mathrm{~cm}^{2} / \mathrm{C}$ 高着色效率。磁控溅射法是一种常用的

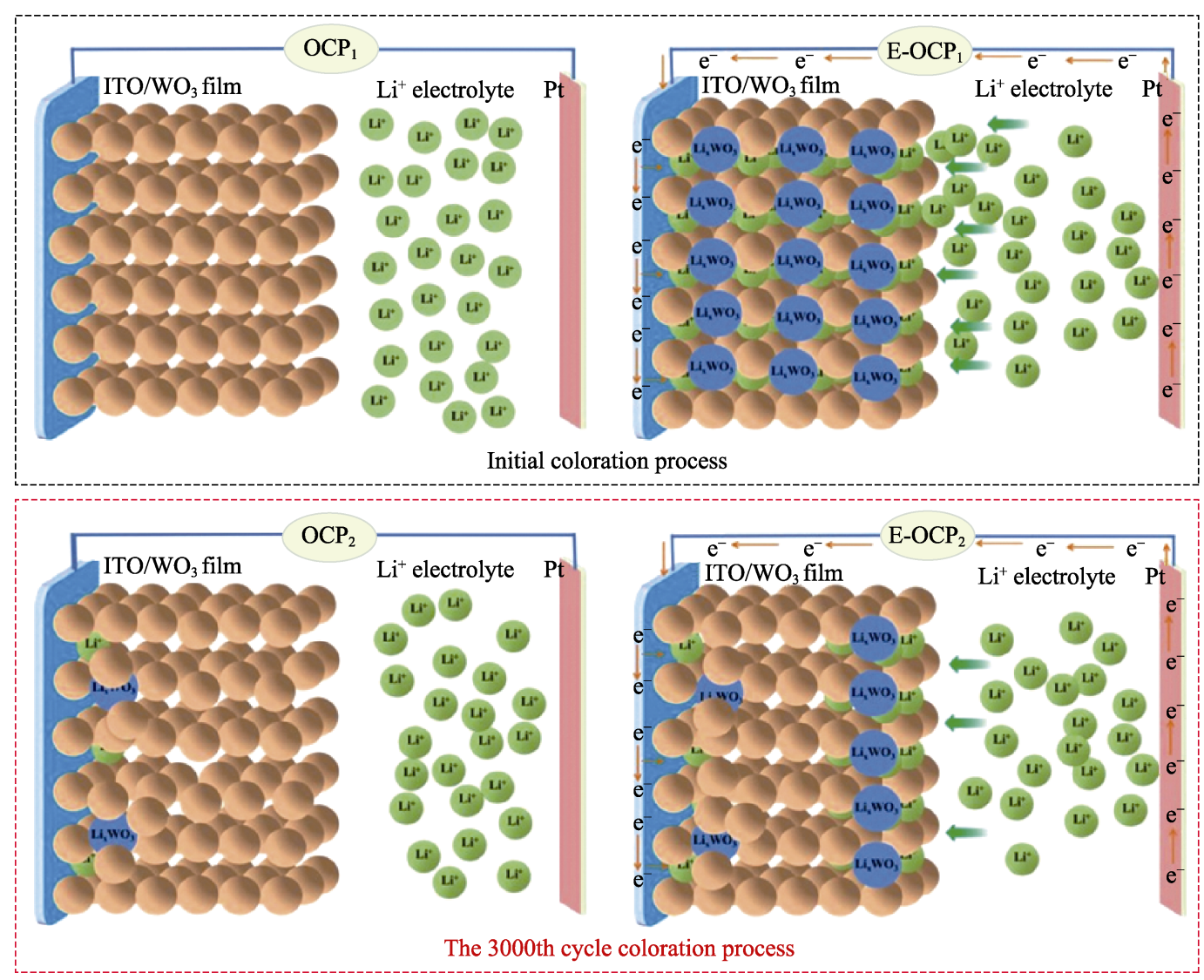

图 1 捕获离子对 $\mathrm{OCP}$ 和插入离子电荷密度影响的示意图 ${ }^{[14]}$

Fig. 1 Schematic diagram of the effect of trapped ions on the OCP and charge density of inserted ions ${ }^{[14]}$ 
物理制备方法, 北京航空航天大学习训刚课题组 ${ }^{[18]}$ 采用磁控溅射法研究了 $\mathrm{WO}_{3}$ 薄膜在 $\mathrm{Ar}$ 和 $\mathrm{O}_{2}$ 气氛中 退火后的性质, 如图 2 所示, 发现在 $\mathrm{Ar}$ 气中氧空位 浓度高, $\mathrm{WO}_{3}$ 薄膜的 $\mathrm{EC}$ 性能更好, 但循环稳定性 变差。

\subsection{2 元素掺杂}

图 3 展示了 2016 2020 年已研究的 $\mathrm{WO}_{3}$ 薄膜掺 杂元素在元素周期表中的分布。 $\mathrm{Co}^{[19]} 、 \mathrm{Ni}^{[20]}$ 、 $\mathrm{Mo}^{[21-22]} 、 \mathrm{Nb}^{[23]} 、 \mathrm{Ti}^{[24-25]}, \mathrm{Ru}^{[26]} 、 \mathrm{Au}^{[27]} 、 \mathrm{Li}^{[28]} 、 \mathrm{Sb}^{[29]}$ 等金属元素掺杂和 $\mathrm{Eu}^{[30-31]} 、 \mathrm{Gd}^{[32]} 、 \mathrm{~Tb}^{[33]} 、 \mathrm{Ce}^{[34]}$ 等稀土元素掺杂能明显增强 $\mathrm{WO}_{3}$ 薄膜的 $\mathrm{EC}$ 性能, 有些元素甚至还表现出其他的功能。中国科学技术 大学徐春叶课题组 ${ }^{[19]}$ 发现 $\mathrm{Co}$ 离子掺杂的 $\mathrm{WO}_{3}$ 膜表 面形貌变化显著, 表现出更高的透射率调制(680 nm 处 $75.4 \%$ )和超过 4000 次的稳定性。该课题组还通 过水热法将 $\mathrm{Tb}$ 离子掺杂到 $\mathrm{WO}_{3}$ 薄膜中 ${ }^{[33]}$, 抑制了 $\mathrm{WO}_{3}$ 的定向生长, 引入的非晶态和多孔网状结构使 $\mathrm{WO}_{3}$ 薄膜具有良好的 $\mathrm{EC}$ 性能, 同时 $\mathrm{WO}_{3}$ 薄膜还具 有光致发光的功能, 可以在 $260 \mathrm{~nm}$ 紫外光下实现绿
色发射。浙江大学涂江平课题组 ${ }^{[23]}$ 研究了 $\mathrm{Nb}$ 掺杂 的 $\mathrm{WO}_{3}$ 薄膜, 具有超快的响应速度, 着色和漂白时 间分别为 3.6 和 $2.1 \mathrm{~s}$ 。

\subsection{3 纳米结构}

纳米结构是通过改变薄膜物理形貌来增大薄膜 与电解质之间的接触面积, 从而达到缩短电荷传输 距离的目的。设计纳米点、纳米线、纳米棒和纳米 片等低维纳米结构已被证明是提高 $\mathrm{WO}_{3}$ 薄膜电致 变色性能的有效策略, 快速的离子/电子转移速度和 更多的活性位点有助于增强 $\mathrm{WO}_{3}$ 薄膜的光学调制 程度和缩短着裉色响应时间。

上海大学高彦峰课题组 ${ }^{[35]}$ 报道了具有 $97.8 \%$ 的 超大光调制范围和 20000 次长循环寿命的 $\mathrm{WO}_{3}$ 量子 点薄膜。习训刚等 ${ }^{[36]}$ 采用电沉积法制备了具有二维 网格结构的 $\mathrm{WO}_{3}$ 薄膜, 着色和漂白时间极短 $(1.27$ 和 $0.93 \mathrm{~s})$, 比平面 $\mathrm{WO}_{3}$ 薄膜 $(2.34$ 和 $2.18 \mathrm{~s}$ ) 快得多, $\mathrm{WO}_{3}$ 薄膜结构见图 4。浙江大学韩高荣课题组 ${ }^{[37]}$ 采 用湿化学方法成功地制备了尺寸可调的电致变色 $\mathrm{WO}_{3}$ 纳米棒, $\mathrm{WO}_{3}$ 纳米棒的平均长度和直径可从

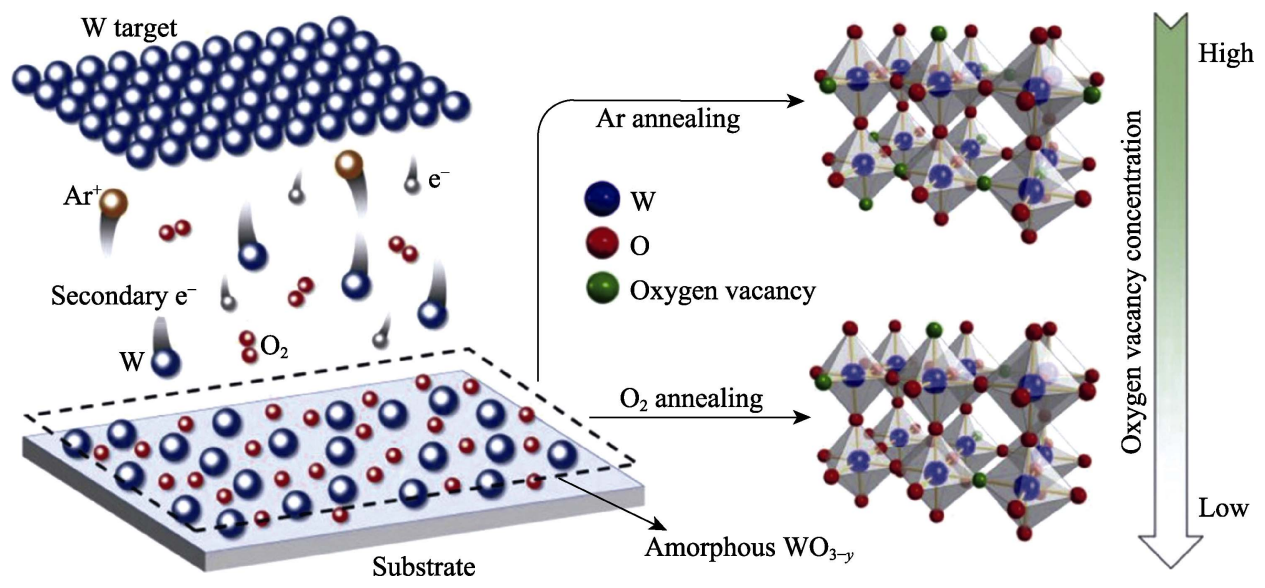

图 $2 \mathrm{WO}_{3}$ 薄膜的制备过程、晶体结构和氩/氧气氛退火引起的氧空位变化 ${ }^{[18]}$

Fig. 2 Illustration of $\mathrm{WO}_{3}$ thin films fabrication process, crystal structure and oxygen vacancy change induced by $\mathrm{Ar} / \mathrm{O}_{2}$ atmosphere annealing ${ }^{[18]}$

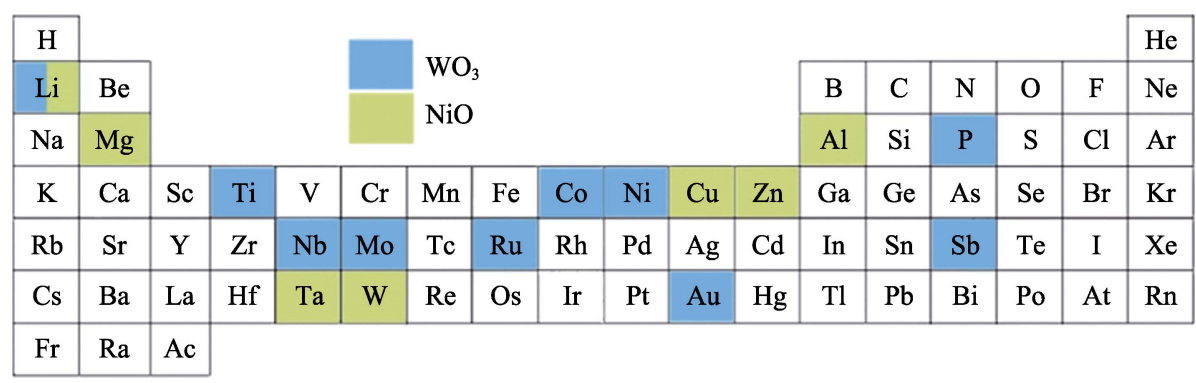

\begin{tabular}{|c|c|c|c|c|c|c|c|c|c|c|c|c|c|c|}
\hline $\mathrm{La}$ & $\mathrm{Ce}$ & $\mathrm{Pr}$ & $\mathrm{Nd}$ & $\mathrm{Pm}$ & $\mathrm{Sm}$ & $\mathrm{Eu}$ & $\mathrm{Gd}$ & $\mathrm{Tb}$ & $\mathrm{Dy}$ & $\mathrm{Ho}$ & $\mathrm{Er}$ & $\mathrm{Tm}$ & $\mathrm{Yb}$ & $\mathrm{Lu}$ \\
\hline $\mathrm{Ac}$ & $\mathrm{Th}$ & $\mathrm{Pa}$ & $\mathrm{U}$ & $\mathrm{Np}$ & $\mathrm{Pu}$ & $\mathrm{Am}$ & $\mathrm{Cm}$ & $\mathrm{Bk}$ & $\mathrm{Cf}$ & $\mathrm{Es}$ & $\mathrm{Fm}$ & $\mathrm{Md}$ & $\mathrm{No}$ & $\mathrm{Lr}$ \\
\hline
\end{tabular}

图 32016 2020 年已研究 $\mathrm{WO}_{3}$ 和 $\mathrm{NiO}$ 薄膜的掺杂元素

Fig. 3 Elements doped to $\mathrm{WO}_{3}$ and $\mathrm{NiO}$ films which researched from 2016 to 2020 


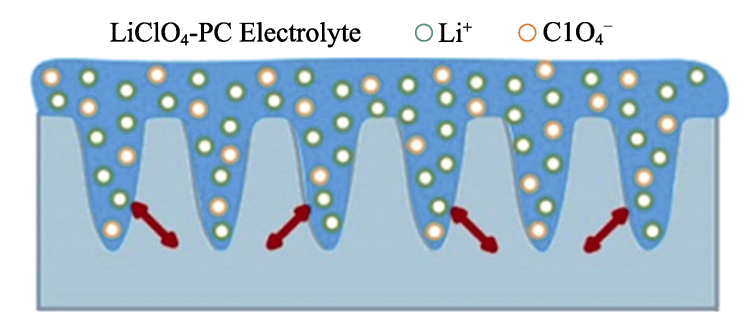

Grid-structured $\mathrm{WO}_{3}$ film

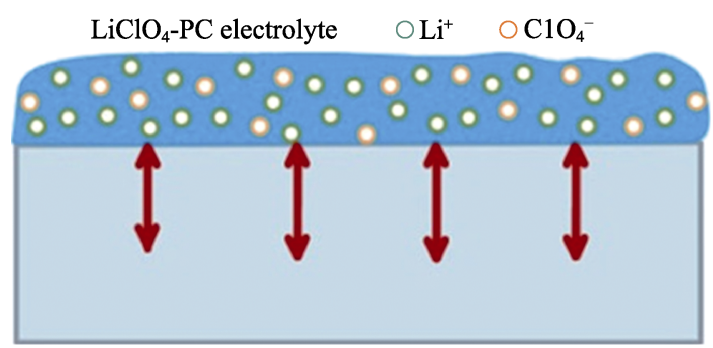

Plane $\mathrm{WO}_{3}$ film

图 $42 \mathrm{D}$ 网格结构和平面 $\mathrm{WO}_{3}$ 膜的电致变色机理图 ${ }^{[36]}$

Fig. 4 Electrochromic mechanism diagram of 2D grid-structured and plane $\mathrm{WO}_{3}$ film ${ }^{[36]}$

$38 \mathrm{~nm} \times 3.2 \mathrm{~nm}$ 增加到 $89 \mathrm{~nm} \times 4.5 \mathrm{~nm}$, 简单地改变纳 米棒的尺寸, 薄膜的响应速度可以提高近 5 倍。

\subsection{4 复合材料}

由于材料的固有特性, 单一的电致变色材料往 往无法兼顾高的电致变色性能和长期稳定性, 利用 复合材料的协同作用可以使材料获得更加丰富的功 能，如将有机和无机材料结合可以同时获得丰富的 颜色变化、快速的切换时间和良好的循环稳定性。 哈尔滨工业大学李圭等 ${ }^{[38]}$ 采用溶剂热法和电聚合 法制备了 $\mathrm{WO}_{3} @ \mathrm{PANI}$ 海胆状结构的复合材料, 表 现出紫色、绿色、黄色、灰色、蓝色等多种颜色变 化, 长期循环性能优异。青岛科技大学聂广明课题 组 ${ }^{[39]}$ 制备的聚 (5-甲酰基吲哚)/ $\mathrm{WO}_{3}$ 蜂窝孔状纳米复 合材料能在深绿色、黄色和黄绿色之间可逆切换, 着色效率高达 $137 \mathrm{~cm}^{2} / \mathrm{C}$ 。

\section{$2 \mathrm{NiO}$ 薄膜研究进展}

\section{$2.1 \mathrm{NiO}$ 的结构和变色机制}

$\mathrm{NiO}$ 晶体是 $\mathrm{NaCl}$ 型面心立方结构, 在实际制备 时 $\mathrm{NiO}$ 薄膜通常为非化学计量比的 $\mathrm{P}$ 型半导体, 存 在 $\mathrm{Ni}^{2+}$ 空位。 $\mathrm{NiO}$ 在碱性溶液和在含 $\mathrm{Li}^{+}$电解液等不 同类型电解质中的电致变色机制完全不同。在碱性 溶液如 $\mathrm{KOH}$ 中的变化可参考 Bode 模型 ${ }^{[40]}, \mathrm{NiO}$ 的 变色过程是从透明的 $\mathrm{Ni}(\mathrm{OH})_{2}$ 转化到有色的 $\mathrm{NiOOH}$, 光谱吸收与 $\mathrm{Ni}^{2+}$ 和 $\mathrm{Ni}^{3+}$ 之间的电荷转移有关。 Passerini 等 ${ }^{[41]}$ 初步提出了 $\mathrm{NiO}$ 薄膜在 $\mathrm{LiClO}_{4}-\mathrm{PC}$ 中 的变色机制, 首先 $\mathrm{NiO}$ 通过不可逆反应变成透明的
$\mathrm{Li}_{y} \mathrm{NiO}_{x}$, 然后 $\mathrm{Li}^{+}$离子和电子的共同嵌入脱出使 $\mathrm{Li}_{y} \mathrm{NiO}_{x}$ 和 $\mathrm{Li}_{(y-z)} \mathrm{NiO}_{x}$ 之间发生可逆的颜色转换, 如 式(2)和(3)。

$$
\begin{gathered}
\mathrm{NiO}_{x}+y \mathrm{Li}^{+}+y \mathrm{e}^{-} \rightarrow \mathrm{Li}_{y} \mathrm{NiO}_{x} \\
\mathrm{Li}_{y} \mathrm{NiO}_{x} \text { (bleached) } \leftrightarrow \mathrm{Li}_{(y-z)} \mathrm{NiO}_{x} \text { (colored) }+z \mathrm{Li}^{+}+z \mathrm{e}^{-}
\end{gathered}
$$

另外还有研究表明 $\mathrm{NiO}$ 薄膜的变色与薄膜表面 离子有关以及在电致变色过程中生成了更高价态的 $\mathrm{Ni}^{4+}$, 这些理论进一步完善了 $\mathrm{NiO}$ 的电致变色机制。

\section{$2.2 \mathrm{NiO}$ 薄膜的衰退机制}

$\mathrm{WO}_{3}$ 和 $\mathrm{NiO}$ 组成的互补型电致变色器件的循环 寿命在很大程度上受到 $\mathrm{NiO}$ 薄膜衰退的限制。对于 $\mathrm{NiO}$ 在碱性电解质中的衰退机制, Bouessaya 等 ${ }^{\left[{ }^{[2]}\right]}$ 为是 $\mathrm{Ni}(\mathrm{OH})_{2}$ 发生自放电导致薄膜被部分降解。 $\mathrm{NiO}$ 在含 $\mathrm{Li}^{+}$的非水电解质中的衰退与 $\mathrm{WO}_{3}$ 相似, $\mathrm{Li}^{+}{ }^{+}$被 $^{2}$ “深陷阱”捕获导致不可逆脱出, 增加了离子扩散阻 力, 从而使 $\mathrm{NiO}$ 薄膜性能下降。习训刚等 ${ }^{[43}$ 利用聚 焦离子束切割器结合二次离子质谱实验研究了 $\mathrm{NiO}$ 薄膜在无机全固态器件中的退化情况, 发现不可逆 捕获的 $\mathrm{Li}^{+}$在 $\mathrm{NiO}$ 薄膜中累积, $\mathrm{NiO}$ 薄膜结构从疏松 变得致密。

\section{$2.3 \mathrm{NiO}$ 薄膜的性能优化}

氧化镍在裉色时为透明态或浅褐色，着色时呈 现深棕色，这种柔和的中性色可与 $\mathrm{WO}_{3}$ 的颜色叠加， 非常适合用于智能窗中。但是 $\mathrm{NiO}$ 的光学调制率通 常不如 $\mathrm{WO}_{3}$, 还存在漂白态的透过率较低、着褪色 响应时间长、长期循环稳定性差等问题。本节从薄 膜的生产方法改进、元素掺杂、纳米结构的设计和 复合材料的引入等方面介绍 $\mathrm{NiO}$ 电致变色性能优化 的研究进展。

\subsection{1制备方法}

同 $\mathrm{WO}_{3}$ 的制备方法类似, $\mathrm{NiO}$ 的制备主要有旋 涂 ${ }^{[44]}$ 、水热 ${ }^{[45-46]}$ 、溶胶-凝胶 ${ }^{[47]}$ 、电沉积 ${ }^{[48}$ 和溅射 ${ }^{[49]}$ 等方法。严辉等 ${ }^{[50]}$ 采用溶胶一凝胶法制备了 $\mathrm{NiO}$ 薄 膜, 并研究了退火温度对 $\mathrm{NiO}$ 薄膜的影响, 经 $350{ }^{\circ} \mathrm{C}$ 退火的 $\mathrm{NiO}$ 薄膜具有 $50.7 \%$ 的透过率调制范 围和 $71.4 \mathrm{~cm}^{2} / \mathrm{C}$ 的着色效率。李圭等 ${ }^{[51]}$ 通过连续改 变磁控溅射时的基底温度, 制备了一种晶体结构从 有序到无序连续变化的 $\mathrm{NiO}$ 薄膜, 如图 5 所示, 这 种 $\mathrm{NiO}$ 薄膜很好地兼顾了优异的 $\mathrm{EC}$ 性能和良好的 循环稳定性。

\subsection{2 元素掺杂}

近期对氧化镍薄膜元素掺杂的研究集中在金属 元素掺杂，如 $\mathrm{Cu}^{[52]} 、 \mathrm{Li}^{[53]} 、 \mathrm{~W}^{[54]}$ 和 $\mathrm{Li}-\mathrm{Mg}^{[55]} 、 \mathrm{Li}-\mathrm{Ta}^{[56]}$ 双元素共掺杂等, 见图 3。Firat 等 ${ }^{[52]}$ 研究了 $\mathrm{Cu}$ 掺杂 


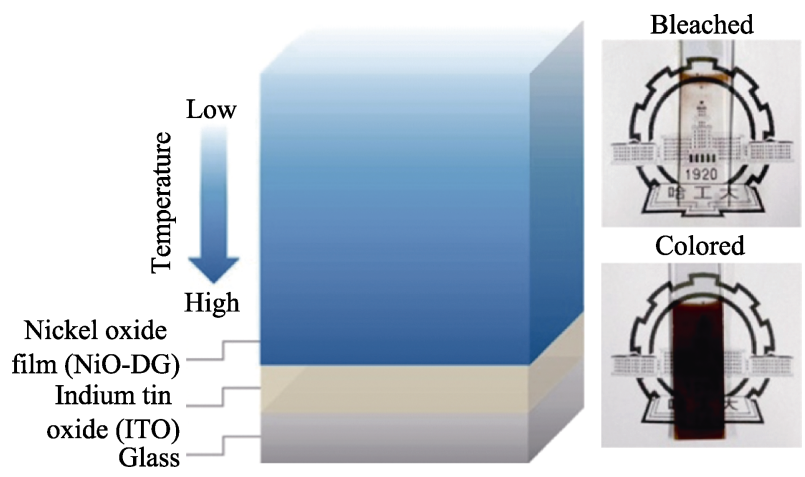

图 5 结晶度梯度变化的 $\mathrm{NiO}$ 薄膜和着褪色态照片 ${ }^{[51]}$

Fig. 5 Schematic of the crystallinity gradient in $\mathrm{NiO}$ film and photos of $\mathrm{NiO}$ film in colored and bleached state ${ }^{[51]}$

$\mathrm{NiO}$ 薄膜的形貌和 $\mathrm{EC}$ 性能, $\mathrm{Cu}$ 掺杂的 $\mathrm{NiO}$ 薄膜具 有极短的颜色响应时间，着色为 $1.77 \mathrm{~s}$ ，褪色为 $2.26 \mathrm{~s}$ 。Lee 等 ${ }^{[54]}$ 采用直流反应磁控溅射法, 以铇镍 合金为靶材制备了 $\mathrm{W}$ 掺杂的 $\mathrm{NiO}$ 薄膜, $\mathrm{W}$ 掺杂能使 纯 $\mathrm{NiO}$ 膜在电化学循环过程中由深陷阱位点引起的 退化降至最低。フ训刚等 ${ }^{[55]}$ 使用射频磁控溅射法在 $\mathrm{NiO}$ 薄膜中共掺杂了 $\mathrm{Mg}$ 和 $\mathrm{Li}$ ，通过预锂化扩大了 $\mathrm{NiO}$ 的间隙, 改善了短波长下 $\mathrm{NiO}$ 薄膜的 $\mathrm{EC}$ 性能。

\subsection{3 纳米结构}

设计纳米结构的 $\mathrm{NiO}$ 可以缩短离子的扩散距离, 提高 $\mathrm{NiO}$ 薄膜的响应速度, 多孔纳米结构还能为离 子传输提供通道, 有效提高 $\mathrm{NiO}$ 薄膜的循环稳定 性。 $\mathrm{Wu}$ 等 ${ }^{[57]}$ 使用电泳沉积法制备了晶粒尺寸在 $10.36 \mathrm{~nm}$ 左右的 $\mathrm{NiO}$ 纳米晶薄膜, 在 $550 \mathrm{~nm}$ 处具有 较大的光调制幅度 $(54.1 \%)$, 切换速度较快 $\left(t_{\mathrm{c}}=7.3 \mathrm{~s}\right.$, $\left.t_{\mathrm{b}}=3.9 \mathrm{~s}\right)$ 。如图 6 所示, 李圭等 ${ }^{[88]}$ 报道了一种简便 $\mathrm{ZnO}$ 模板辅助水解法制备的 $\mathrm{NiO}$ 纳米管阵列膜, 具 有极大的透过率调制 (78.5\%)和快速的开关响应时
间 $\left(t_{\mathrm{c}}=3.92 \mathrm{~s}, t_{\mathrm{b}}=3.43 \mathrm{~s}\right)$ 。Ren 等 ${ }^{[59]}$ 采用光敏溶胶一凝 胶法制备了多孔阵列的 $\mathrm{NiO}$ 图案膜, 与致密的 $\mathrm{NiO}$ 膜相比, 多孔 $\mathrm{NiO}$ 图案膜具有更好的电致变色性能 和更长的使用寿命 (3000 次)。

\subsection{4 复合材料}

$\mathrm{NiO}$ 薄膜的低导电性导致了开关速度慢、着色 效率低的问题，利用复合材料的协同作用可以改善 $\mathrm{NiO}$ 薄膜的电致变色性能。中国科学院长春光学精 密机械与物理研究所刘星元团队 ${ }^{[60]}$ 采用简单的一 步电子束沉积法, 在室温条件下成功地制备了透 明、导电、无需 ITO 的 $\mathrm{NiO} / \mathrm{Ag} / \mathrm{NiO}$ 膜，该薄膜在 可见光区平均透过率超过 70\%。东华大学王宏志课 题组 ${ }^{[61]}$ 通过金属有机骨架(MOF) 的两步热解法制备 了分级多孔 $\mathrm{NiO} @ \mathrm{C}$ 薄膜, 制备流程见图 7, 调节 C 的含量可改善薄膜的电化学和 $\mathrm{EC}$ 性能, 最佳 $\mathrm{C}$ 含 量的多孔 $\mathrm{NiO} @ \mathrm{C}$ 薄膜具有极快的切换速度 $\left(t_{\mathrm{c}}=\right.$ $\left.0.46 \mathrm{~s}, t_{\mathrm{b}}=0.25 \mathrm{~s}\right)$ 、超高的着色效率 $\left(113.5 \mathrm{~cm}^{2} / \mathrm{C}\right)$ 和显 著的循环稳定性 20000 次)。

\section{3 基于 $\mathrm{WO}_{3}$ 和 $\mathrm{NiO}$ 的电致变色器件}

传统的电致变色器件为五层结构, $\mathrm{WO}_{3}$ 和 $\mathrm{NiO}$ 通常作为电致变色层和离子存储层，二者中间是离 子传导层，两侧是用于传输电子的透明导电层。电致 变色器件的整体性能不仅与各层薄膜的性质有关, 还 取决于层与层之间的协同作用和器件结构的设计。

\section{1 透明导电层}

透明导电层是电致变色器件的重要组成部分, 起到连接器件与外电路的作用。常见的透明导电薄 膜包括金属薄膜和金属氧化物半导体膜，在智能窗

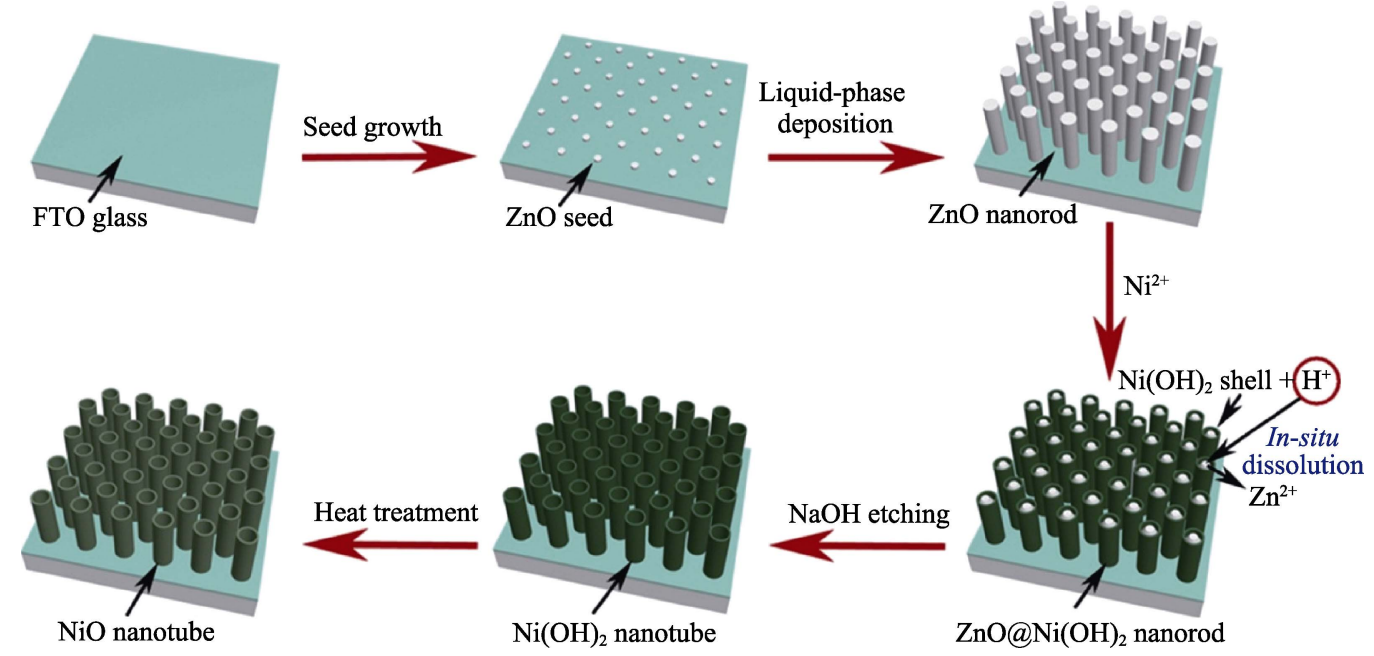

图 $6 \mathrm{NiO}$ 纳米管阵列的制备示意图 ${ }^{[58]}$

Fig. 6 Facile preparation of aligned $\mathrm{NiO}$ nanotube arrays ${ }^{[58]}$ 


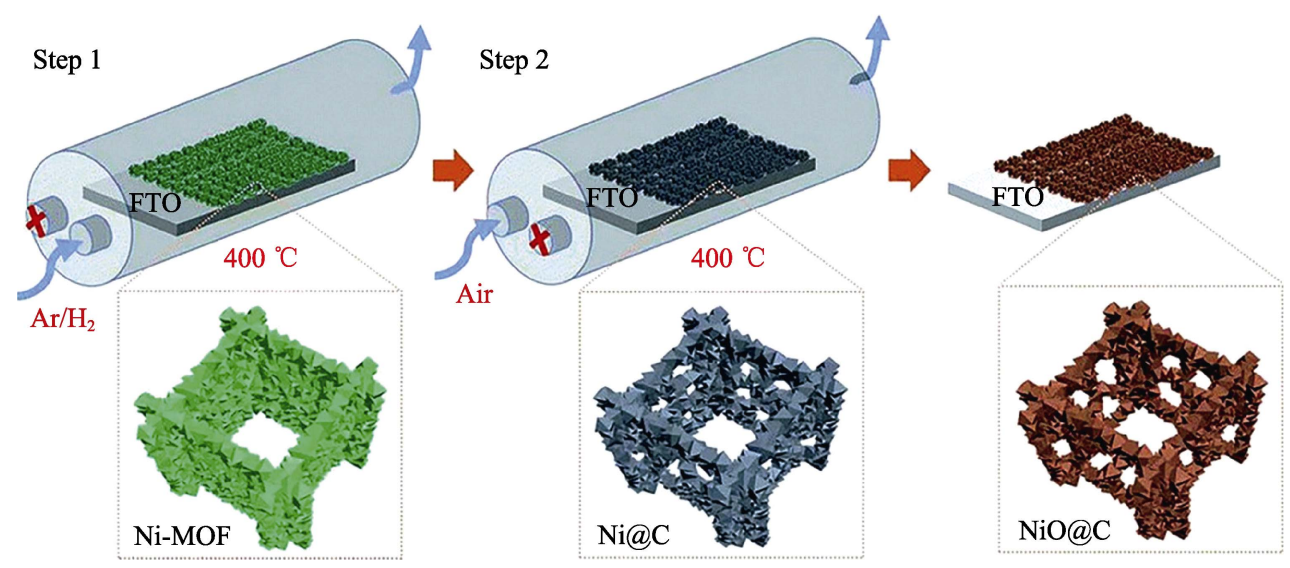

图 7 多孔分层 $\mathrm{NiO} @ \mathrm{C}$ 薄膜的制备示意图 ${ }^{[61]}$

Fig. 7 Preparation procedures of the hierarchical-porous $\mathrm{NiO} @ \mathrm{C}$ film ${ }^{[61]}$

等应用中要求透明导电膜同时具有高透过率和高导 电性。金属虽然具有良好的导电性，但是在可见光 波段不透明，极薄的金属膜可以解决透光问题，然 而制备较为困难, 容易引入不连续的岛状结构, 反 而增加电阻率。金属氧化物薄膜因在可见光区具有 很好的透过性而被广泛使用, 常见的有 $\mathrm{In}_{2} \mathrm{O}_{3}: \mathrm{Sn}(\mathrm{ITO})$, $\mathrm{SnO}_{2}: \mathrm{F}(\mathrm{FTO})$ 和 $\mathrm{ZnO}: \mathrm{Al}(\mathrm{AZO})$ 等。

ITO 的研究和应用最多, ITO 不仅具有较低的电 阻率和高可见光透过率，还具有与基底结合牢固、 抗擦伤的优点。然而单层的 ITO 存在电导率与透过 率难以平衡的问题, 因此一种新的 “电介质/金属/ 电介质”三层结构透明导电膜得到了人们的关注。习 训刚等 ${ }^{[62]}$ 采用磁控溅射法在玻璃基底上制备了具 有低电阻和高透明性的堆叠 ITO/Ag/ITO(IAI)电极。 IAI $(50 \mathrm{~nm} / 5 \mathrm{~nm} / 30 \mathrm{~nm})$ 薄膜的薄层电阻低至 $7.4 \Omega$, 在 $\mathrm{NiO}_{x} 、 \mathrm{WO}_{3}$ 电致变色薄膜和完整的 Glass/IAI/ $\mathrm{NiO}_{x} / \mathrm{LiClO}_{4}-\mathrm{PC}-\mathrm{PMMA} / \mathrm{WO}_{3} / \mathrm{IAI} / \mathrm{Glass}$ 器件中均表 现出优异的性能。为了解决 ITO 导电薄膜中 In 元素 稀少、有毒造成的高成本和污染性的问题, 该课题 组还研究了 AZO 薄膜的性能 ${ }^{[63]}$, 其品质因数高达 $12.14 \times 10^{-3} \Omega^{-1}$, 平均透射率为 $92.2 \%$, 但 $\mathrm{AZO}$ 的电 学性能还有待提高。

另外，具有高机械稳定性的柔性透明导电膜的 研究也备受关注。フ训刚等 ${ }^{[64]}$ 采用磁控溅射法在柔 性透明 PET 基底上沉积 ITO 薄膜, 并继续逐层沉积 $\mathrm{NiO}_{X} / \mathrm{LiTaO}_{3} / \mathrm{WO}_{3} / \mathrm{ITO}$ 制成了柔性无机电致变色器 件, 具有较高着色效率 $\left(68.5 \mathrm{~cm}^{2} / \mathrm{C}\right)$ 。由于 ITO 本身 的刚性限制，在柔性基底上制备的 ITO 薄膜效果不 佳, 许多新的柔性透明导电材料如金属纳米线、金 属网格 ${ }^{[65]}$ 、石墨烯、碳纳米管和 PEDOT:PSS ${ }^{[66-67]}$ 等导电聚合物已经得到广泛研究, 并有希望成为 ITO 的替代品。

\section{2 离子传导层}

在互补型电致变色器件中, 离子传导层位于阴 极和阳极电致变色材料中间, 起到提供变色阳离子 和阻隔电子的作用。离子传导层通常选用高离子电 导率、低电子电导率的透明电解质, 包括液态电解 质、凝胶电解质和固态电解质。

液态电解质的离子迁移率最高, 能为电致变色 器件提供快速的可逆反应, 北京航空材料研究院颜 悦团队 ${ }^{[68]}$ 分别研究了 $\mathrm{LiClO}_{4} 、 \mathrm{LiPF}_{6} 、$ LiTFSI 三种 含有不同锂盐的液体电解质对 $\mathrm{NiO} 、 \mathrm{WO}_{3}$ 薄膜和 Glass $/ \mathrm{ITO} / \mathrm{WO}_{3} / \mathrm{Li}^{+} / \mathrm{NiO} / \mathrm{ITO} / \mathrm{Glass}$ 结构电致变色器 件的影响, 不同电致变色膜在同一电解液中的电压 和阻抗具有明显差异。液态电解质虽然具有优异的 离子电导率, 但其腐蚀性和流动性往往造成封装上 的困难和漏液风险, 构建多孔结构的离子传导层或 引入吸附毡均是比较有效的解决策略。

凝胶电解质由于透明度高、导电性好和机械稳 定性优异的特点而备受青睐, 可用于柔性器件中, 如 PMMA- $\mathrm{LiClO}_{4}$ 等。苏州纳米所赵志刚等 ${ }^{[69]}$ 研制 了一种新型的独立芳纶纳米纤维凝胶聚合物电解质, 具有良好的耐热性和成膜能力, 利于 $\mathrm{WO}_{3}$ 和 $\mathrm{NiO}$ 电 致变色器件的组装。Wootthikanokkhan 等 ${ }^{[70]}$ 将明胶、 乙烯一丙烯酸共聚物离聚物树脂(EAA) 与甘油、 $\mathrm{LiClO}_{4}$ 、甲醛等混合制成凝胶电解质，实现了很高 的离子电导率 $(4.46 \mu \mathrm{S} / \mathrm{cm})$ 。

固态电解质具有良好的稳定性和耐候性，便于 封装和大规模制备, 在全固态电致变色器件中具有 极其重要的地位, 如 $\mathrm{Ta}_{2} \mathrm{O}_{5}{ }^{[71]} 、 \mathrm{ZrO}_{2}{ }^{[72]} 、 \mathrm{LiF}^{[73]}$ 、 $\mathrm{LiPON}^{[74]}$ 等。锂基固态电解质的研究较为成熟, 李 圭课题组 ${ }^{[73]}$ 采用电阻蒸发法制备了 $\mathrm{LiF}$ 无机固态电 解质, 在无机全固态 glass $/ \mathrm{ITO} / \mathrm{WO}_{3} / \mathrm{LiF} / \mathrm{NiO} / \mathrm{ITO}$ 器 件中表现出良好的性能。中国科学院上海硅酸盐研 
究所包山虎团队 ${ }^{[75]}$ 通过锂铝靶共溅射制备出的 $\mathrm{Li}_{x} \mathrm{AlO}_{z}$ 薄膜具有高透明度、良好的离子导电性和超 高稳定性，该团队还制备了 $10 \mathrm{~cm} \times 10 \mathrm{~cm}$ 的大型全 固态电致变色器件 (ITO/ $\left.\mathrm{NiO}_{x} / \mathrm{Li}_{x} \mathrm{AlO}_{z} / \mathrm{WO}_{3} / \mathrm{ITO}\right)$, 如 图 8 所示。固态电解质在应用和制备上具有独特的 便捷性，但是离子电导率低的问题仍是当前固态电 解质的研究重点。

\section{3 器件结构设计}

$\mathrm{WO}_{3}$ 和 $\mathrm{NiO}$ 薄膜组成的电致变色器件通常具有 标准的“三明治”结构, 离子传导层中的阳离子在电 场的作用下会从 $\mathrm{NiO}$ 薄膜中脱出并嵌入到 $\mathrm{WO}_{3}$ 薄 膜中, 使 $\mathrm{WO}_{3}$ 和 $\mathrm{NiO}$ 电致变色膜同时着色, 反之二 者同时裉色。表 1 总结了近五年来由 $\mathrm{WO}_{3}$ 和 $\mathrm{NiO}$ 组成的电致变色器件的结构与响应时间 $\left(t_{\mathrm{c}} 、 t_{\mathrm{b}}\right)$ 、着 色效率 $(C E)$ 和光调制范围 $(\Delta T)$ 等性能对比。

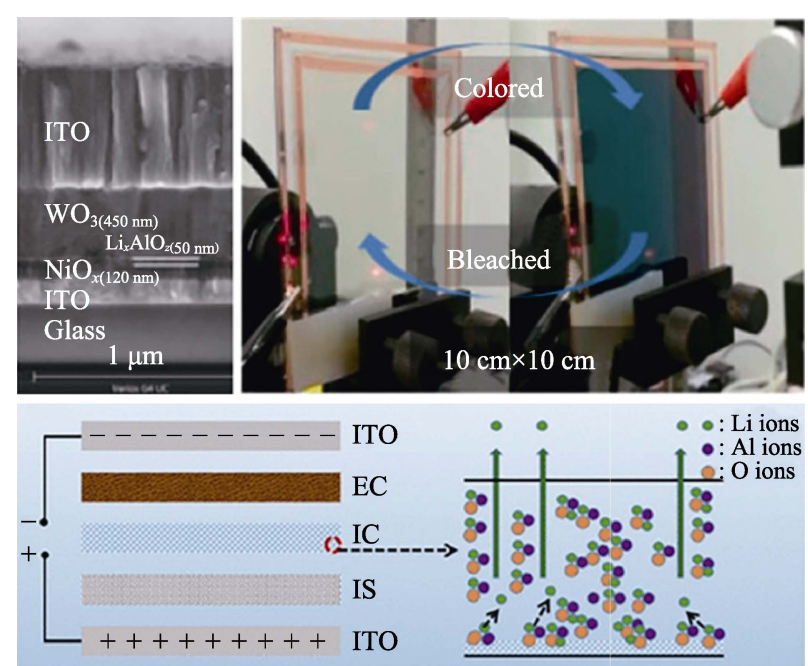

图 8 大型全固态器件结构示意图和照片 ${ }^{[75]}$

Fig. 8 Schematic diagram of large-scale all-solid-state device structure and photograph ${ }^{[75]}$

表 $12016 \sim 2020$ 年基于 $\mathrm{WO}_{3}$ 和 $\mathrm{NiO}$ 薄膜的电致变色器件结构与性能对比

Table 1 Comparison of structure and performance of ECDs based on $\mathrm{WO}_{3}$ and NiO films researched from 2016 to 2020

\begin{tabular}{|c|c|c|c|c|c|c|c|}
\hline Year & Device structure & $t_{\mathrm{c}} / \mathrm{s}$ & $t_{\mathrm{b}} / \mathrm{s}$ & $\mathrm{CE} /\left(\mathrm{cm}^{2} \cdot \mathrm{C}^{-1}\right)$ & $\Delta T / \%$ & Cycles & Ref. \\
\hline 2016 & $\mathrm{ITO} / \mathrm{NiO}_{x} / \mathrm{ZrO}_{2}: \mathrm{H} / \mathrm{WO}_{3} / \mathrm{ITO}$ & 116 & 108 & - & 65.2 & 2000 & [72] \\
\hline 2016 & $\mathrm{ITO} / \mathrm{NiO}_{x} / \mathrm{Ta}_{2} \mathrm{O}_{5}: \mathrm{H} / \mathrm{WO}_{3} / \mathrm{ITO}$ & - & - & - & 60 & - & [76] \\
\hline 2016 & $\mathrm{ITO} / \mathrm{WO}_{3} / \mathrm{LiClO}_{4}-\mathrm{PC}-\mathrm{PMMA} / \mathrm{NiO}_{x} / \mathrm{ITO}$ & 4.5 & 1.7 & - & 51.7 & 50000 & [77] \\
\hline 2016 & Glass $/ \mathrm{ITO} / \mathrm{WO}_{3} / \mathrm{LiNbO}_{3} / \mathrm{NiO}_{x} / \mathrm{ITO}$ & 45 & 25 & - & 65 & - & [78] \\
\hline 2016 & ITO/NiO $: \mathrm{Ti} / \mathrm{PVB}\left(\mathrm{Li}^{+}\right) / \mathrm{WO}_{3} / \mathrm{ITO}$ & 4.4 & 3.2 & 96 & 60 & - & [79] \\
\hline 2017 & Glass/ITO/WO $/ \mathrm{WV}_{3} / \mathrm{PB}-\mathrm{GPEF} / \mathrm{Ni}_{1-x} \mathrm{O} / \mathrm{ITO} /$ Glass & 9.5 & 16 & 175.34 & 65.8 & 3000 & [80] \\
\hline 2017 & Glass /ITO/NiO $/$ electrolyte/ $\mathrm{WO}_{3} / \mathrm{ITO}$ & 7 & 2 & - & 70 & 300 & [81] \\
\hline 2017 & Glass $/ \mathrm{ITO} / \mathrm{NiO} / \mathrm{Si}_{3} \mathrm{~N}_{4} / \mathrm{LiNbO}_{3} / \mathrm{Si}_{3} \mathrm{~N}_{4} / \mathrm{WO}_{3} / \mathrm{ITO}$ & - & - & - & 43 & - & [82] \\
\hline 2017 & $\mathrm{ITO} / \mathrm{NiO} / \mathrm{Ta}_{2} \mathrm{O}_{5} / \mathrm{LiNbO}_{3} / \mathrm{WO}_{3} / \mathrm{ITO}$ & - & - & - & 34 & - & [83] \\
\hline 2018 & Glass/ITO/NiO/ $/ \mathrm{Si}_{3} \mathrm{~N}_{4} / \mathrm{Li}_{x} \mathrm{Mg}_{y} \mathrm{~N} / \mathrm{WO}_{3} / \mathrm{ITO}$ & - & - & 77 & 40 & 1000 & [84] \\
\hline 2018 & Glass/ITO/ $\mathrm{WO}_{3} / \mathrm{Li}_{2.5} \mathrm{TaO}_{x} / \mathrm{NiO} / \mathrm{ITO}$ & 30 & 30 & 63 & 40 & 300 & [71] \\
\hline 2018 & $\mathrm{FTO} / \mathrm{WO}_{3} /$ gel polymer electrolyte/NiO/FTO & 1.2 & 2.6 & - & 43.81 & 20000 & [85] \\
\hline 2018 & Glass/ITO/ $\mathrm{WO}_{3}: \mathrm{H} / \mathrm{Ta}_{2} \mathrm{O}_{5} / \mathrm{NiO}_{x} / \mathrm{ITO}$ & - & - & 24.3 & 42 & 300 & [86] \\
\hline 2018 & Glass/ITO/WO $/ \mathrm{WiPON}_{3} \mathrm{NiO} / \mathrm{ITO}$ & - & - & - & 40 & - & [74] \\
\hline 2018 & Glass/ITO/Li $\mathrm{NiO}_{y} / \mathrm{LiTaO}_{3} / \mathrm{WO}_{3} / \mathrm{ITO}$ & 13 & 3.5 & 42 & 40 & 7000 & [87] \\
\hline 2018 & ITO/NiO $/ \mathrm{Ta}_{2} \mathrm{O}_{5} / \mathrm{LiNbO}_{3} / \mathrm{Ta}_{2} \mathrm{O}_{5} / \mathrm{WO}_{3} / \mathrm{ITO}$ & - & - & 98 & 52.5 & 10000 & [88] \\
\hline 2018 & $\mathrm{ITO} / \mathrm{NiO} / \mathrm{ZrO}_{2} / \mathrm{LiNbO}_{3} / \mathrm{WO}_{3} / \mathrm{ITO}$ & - & - & 24.3 & 53 & - & [89] \\
\hline 2018 & $\mathrm{ITO} / \mathrm{NiO} / \mathrm{Ta}_{2} \mathrm{O}_{5} / \mathrm{LiNbO}_{3} / \mathrm{WO}_{3} / \mathrm{ITO} / \mathrm{Glass}$ & 10 & 7 & - & 71.7 & - & [90] \\
\hline 2019 & Glass/IAI/ $\mathrm{NiO}_{x} / \mathrm{LiClO}_{4}$-PC-PMMA/ $\mathrm{WO}_{3} / \mathrm{IAI} /$ Glass & 2.25 & 2.02 & 31.7 & 55 & - & [62] \\
\hline 2019 & $\mathrm{ITO} / \mathrm{NiO}_{x} / \mathrm{Li}_{x} \mathrm{AlO}_{z} / \mathrm{WO}_{3} / \mathrm{ITO}$ & 5.7 & 2.2 & 76.45 & 74.4 & 10000 & [75] \\
\hline 2019 & $\mathrm{ITO} / \mathrm{WO}_{3}-\mathrm{Nb}_{2} \mathrm{O}_{5} / \mathrm{Nb}_{2} \mathrm{O}_{5} / \mathrm{NiVO}_{x} / \mathrm{ITO}$ & 7 & 0.7 & - & 33 & 30000 & [91] \\
\hline 2019 & $\mathrm{ITO} / \mathrm{WO}_{3} / \mathrm{LiClO}_{4}$-PC-PMMA/NiO/ITO & 3.2 & 1.1 & 130.8 & 45 & 1000 & [92] \\
\hline 2019 & ITO $/ \mathrm{NiO}_{x} / \mathrm{Ta}_{2} \mathrm{O}_{5} / \mathrm{LiNbO}_{3} / \mathrm{Ta}_{2} \mathrm{O}_{5} / \mathrm{WO}_{3} / \mathrm{ITO}$ & 18.4 & 9.5 & - & 55.2 & 2500 & [93] \\
\hline 2019 & $\mathrm{ITO} / \mathrm{NiO}_{x} / \mathrm{Ta}_{2} \mathrm{O}_{5} / \mathrm{WO}_{3} / \mathrm{ITO}$ & 13 & 2 & - & 70.9 & - & [94] \\
\hline 2020 & Glass $/ \mathrm{ITO} / \mathrm{WO}_{3} / \mathrm{LiF} / \mathrm{NiO} / \mathrm{ITO}$ & 9.6 & 4 & 88.5 & 58.9 & 450 & [73] \\
\hline 2020 & ITO/ $\mathrm{WO}_{3} / \mathrm{Gelatin} / \mathrm{NiO} / \mathrm{ITO}$ & 10 & 50 & 60.38 & 43.35 & - & [70] \\
\hline 2020 & $\mathrm{ITO} / \mathrm{Li}-\mathrm{NiO} / \mathrm{Li}^{-} \mathrm{WO}_{3} / \mathrm{ITO}$ & 8.6 & 1.7 & 87.5 & 32 & 1000 & [95] \\
\hline 2020 & ITO/WO $/ \mathrm{WiClO}_{4}$-PC-PMMA-ACN/NiO/ITO & 1.2 & 1.5 & 243 & 51.27 & 20000 & [96] \\
\hline 2020 & $\mathrm{ITO} / \mathrm{WO}_{3} / \mathrm{LiNbO}_{3} / \mathrm{Al}^{-\mathrm{LiNiO}_{x} / \mathrm{ITO}}$ & 17.9 & 4.1 & - & 44 & 5000 & [97] \\
\hline
\end{tabular}


一个标准的 $\mathrm{ECD}$ 由透明导电层、电致变色层、 离子传导层、离子存储层和透明导电层五部分组成, 按制备方式的不同又可分为单片式和夹层式两种结 构。单片式通常是采用磁控溅射法在基底上连续沉 积多层薄膜, 离子传导层为陶瓷等无机固态电解质, 这种结构由于各膜层均是固体又被称为全固态电致 变色器件, 如图 9(a)所示。夹层式的 ECD 是先在两 玻璃基底上分别制备 $\mathrm{WO}_{3}$ 和 $\mathrm{NiO}$ 薄膜, 再通过层 压、胶合等方式组装成器件, 如图 9(b)所示, 这是一 种简便的组装方式, 液态电解质或凝胶电解质均可 用于夹层式 $\mathrm{ECD}$ 中。

フ训刚等 ${ }^{[71]}$ 采用磁控溅射法在单层的 ITO 玻璃 上连续贼射沉积制备了单片式电致变色器件(Glass/ ITO $/ \mathrm{WO}_{3} / \mathrm{Li}_{2.5} \mathrm{TaO}_{x} / \mathrm{NiO} / \mathrm{ITO}$ ), 并研究了 $\mathrm{Li}_{2.5} \mathrm{TaO}_{x}$ 厚 度对器件的影响。该课题组还制备了 $\mathrm{ITO} / \mathrm{WO}_{3} /$ $\mathrm{LiClO}_{4}-\mathrm{PC}-\mathrm{PMMA} / \mathrm{NiO}_{x} / \mathrm{ITO}$ 夹层式结构的全固态 电致变色器件 ${ }^{[77]}$, 具有超过 50000 次的超高循环耐 久性。

电解质层阻挡电子的能力较差, 容易造成器件 漏电流和差的光学记忆效应, 因此人们在五层结构 $\mathrm{ECD}$ 的基础上提出了七层结构器件, 如图 9(c)所 示。在电解质层两侧增加保护层如 $\mathrm{ZrO}_{2}{ }^{[98]} 、 \mathrm{Ta}_{2} \mathrm{O}_{5}{ }^{[88]}$ 等, 可以使器件获得更高的着色效率、更好的光记 忆效果和更长的循环寿命, 但响应速度和透光率会 因此受到一定影响。才训刚等 ${ }^{[88}$ 制备了七层结构 $\mathrm{ECD}\left(\mathrm{ITO} / \mathrm{NiO}_{X} / \mathrm{Ta}_{2} \mathrm{O}_{5} / \mathrm{LiNbO}_{3} / \mathrm{Ta}_{2} \mathrm{O}_{5} / \mathrm{WO}_{3} / \mathrm{ITO}\right), \quad$ 相 比于无 $\mathrm{Ta}_{2} \mathrm{O}_{5}$ 保护的五层结构器件来说具有低漏电 流、 $98 \mathrm{~cm}^{2} / \mathrm{C}$ 的高着色效率和 10000 次循环寿命。

锂化是一种常见的提升薄膜电致变色性能的手 段, 将 $\mathrm{Li}^{+}$引入到电致变色薄膜中替代电解质是一 (a)

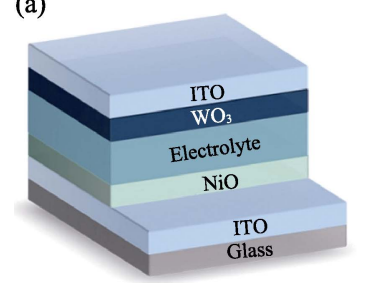

(c)

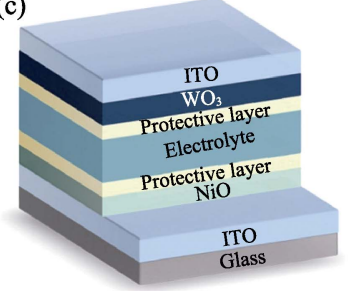

(b)

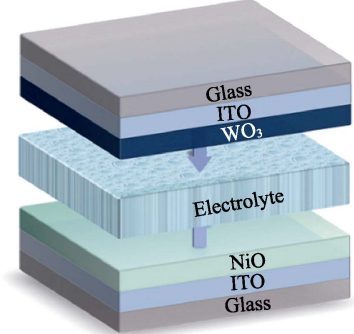

(d)

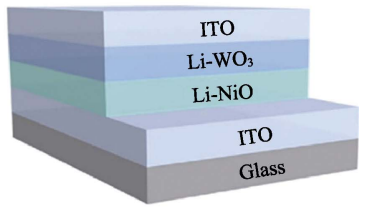

图 $9 \mathrm{ECD}$ 的结构示意图

Fig. 9 Structural schematic diagram of ECD

(a) Monolithic ECD; (b) Laminated ECD; (c) Seven-layered ECD; (d) Four-layered ECD ${ }^{[95]}$
种新的器件结构设计思路, 李圭等 ${ }^{[95}$ 提出了一种四 层结构 $\mathrm{ITO} / \mathrm{Li}-\mathrm{NiO} / \mathrm{Li}^{-} \mathrm{WO}_{3} / \mathrm{ITO}$ 全固态电致变色器 件, 将 $\mathrm{Li}^{+}$直接蒸发在 $\mathrm{WO}_{3}$ 和 $\mathrm{NiO}$ 薄膜上, 取代了 传统结构中的离子传导层, 如图 9(d)所示, $\mathrm{Li}^{+}$直接 在 $\mathrm{WO}_{3}$ 和 $\mathrm{NiO}$ 层之间转移使得器件的总电阻变低, 响应速度变快, 但这种结构对器件光调制幅度和稳 定性的影响还有待进一步的研究。总之, 每种器件 结构都有其独特的优势, 并由各组成成分的综合性 能决定, 在实际生产设计时应针对不同的应用场景 和使用需求选择合适的组分和器件结构。

\section{4 结论与展望}

本文综述了基于 $\mathrm{WO}_{3}$ 和 $\mathrm{NiO}$ 的电致变色器件 近年来的研究进展, 重点讨论了电致变色层 $\mathrm{WO}_{3}$ 和 离子存储层 $\mathrm{NiO}$ 薄膜的研究现状, 总结了器件其他 组分和组装方式发挥的作用和典型器件性能对比。 基于 $\mathrm{WO}_{3}$ 和 $\mathrm{NiO}$ 的电致变色器件具有驱动电压低 和双稳态的性能, 在节能领域尤其是智能窗的应用 中已趋于成熟, 目前美国 Sage-Glass、View Inc、德 国 EControl-Glas 以及瑞典 Chromo Genics 等多家公 司均可实现电致变色玻璃的大规模工业化生产。但 国内的大多数研究还处于实验室或中试阶段, 在智 能窗的生产尤其是在提高大尺寸全器件的稳定性和 完善工艺等方面仍然面临着巨大的挑战, 虽然近几 年国内的学者们已经对此做了诸多努力, 但大都集 中在改善单层薄膜性能的研究上, 缺乏对电致变色 全器件的持续研究, 进一步探究全器件的性能和突 破工业生产的技术瓶颈仍是当前的研究重点。除了 智能窗以外, 工作温度范围宽、化学稳定性好、循 环寿命长等优点使电致变色器件也非常适合用于室 外环境, 目前已有许多学者致力于开发电致变色器 件在电子领域的应用, 特别是在静态图像显示、户 外广告、仪表显示等领域的前景可待。

\section{参考文献:}

[1] DEB S K. A novel electrophotographic system. Applied Optics, 1969, 8(S1): 192-195.

[2] PATEL K J, BHATT G G, RAY J R, et al. All-inorganic solid-state electrochromic devices: a review. Journal of Solid State Electrochemistry, 2017, 21(2): 337-347.

[3] JIA H X, CAO X, JIN P S. Advances in inorganic all-solid-state electrochromic materials and devices. Journal of Inorganic Materials, 2020, 35(5): 511-524.

[4] GRANQVIST C G. Handbook of Inorganic Electrochromic Materials. Amsterdam: Elsevier, 1995: 4-5.

[5] MCINTYRE J D E, BASU S, PECK W F, et al. Cation insertion reactions of electrochromic tungsten and iridium oxide-films. 
Physical Review B, 1982, 25(12): 7242-7254.

[6] EREN E, ALVER C, KARACA G Y, et al. High-performance flexible complementary electrochromic device based on plasma modified $\mathrm{WO}_{3}$ nano hybrids and $\mathrm{V}_{2} \mathrm{O}_{5}$ nanofilm with low operation voltages. Electroanalysis, 2018, 30(9): 2099-2109.

[7] HUANG H, TIAN J, ZHANG W K, et al. Electrochromic properties of porous $\mathrm{NiO}$ thin film as a counter electrode for $\mathrm{NiO} / \mathrm{WO}_{3}$ complementary electrochromic window. Electrochimica Acta, 2011, 56(11): 4281-4286.

[8] DEB S K. Optical and photoelectric properties and color centers in thin-films of tungsten oxide. Philosophical Magazine, 1973, 27(4): $801-822$.

[9] FAUGHNAN B W, CRANDALL $\mathrm{R}$ S, HEYMAN $\mathrm{P}$ M. Electrochromism in $\mathrm{WO}_{3}$ amorphous films. Rca Review, 1975, 36(1): 177-197.

[10] SCHIRMER O F, WITTWER V, BAUR G, et al. Dependence of $\mathrm{WO}_{3}$ electrochromic absorption on crystallinity. Journal of the Electrochemical Society, 1977, 124(5): 749-753.

[11] ZHOU K L, WANG H, LIU J B, et al. The mechanism of trapped ions eroding the electrochromic performances of $\mathrm{WO}_{3}$ thin films. International Journal of Electrochemical Science, 2018, 13(8): 7335-7346.

[12] ZHOU K L, WANG H, LIU J B, et al. Ions transport control in electrochromic $\mathrm{WO}_{3}$ film for the cyclic stability study. Journal of the Electrochemical Society, 2020, 167(10): 106502.

[13] PAN J B, WANG Y, ZHENG R Z, et al. Directly grown highperformance $\mathrm{WO}_{3}$ films by a novel one-step hydrothermal method with significantly improved stability for electrochromic applications. Journal of Materials Chemistry A, 2019, 7(23): 13956-13967.

[14] CAI G F, TU J P, ZHOU D, et al. Growth of vertically aligned hierarchical $\mathrm{WO}_{3}$ nano-architecture arrays on transparent conducting substrates with outstanding electrochromic performance. Solar Energy Materials and Solar Cells, 2014, 124: 103-110.

[15] COSTA C, PINHEIRO C, HENRIQUES I, et al. Inkjet printing of Sol-Gel synthesized hydrated tungsten oxide nanoparticles for flexible electrochromic devices. ACS Applied Materials \& Interfaces, 2012, 4(3): 1330-1340.

[16] CAI G F, CUI M Q, KUMAR V, et al. Ultra-large optical modulation of electrochromic porous $\mathrm{WO}_{3}$ film and the local monitoring of redox activity. Chemical Science, 2016, 7(2): 1373-1382.

[17] CAI G F, DARMAWAN P, CHENG X, et al. Inkjet printed large area multifunctional smart windows. Advanced Energy Materials, 2017, 7(14): 1602598.

[18] YU H, GUO J J, WANG C, et al. Essential role of oxygen vacancy in electrochromic performance and stability for $\mathrm{WO}_{3-y}$ films induced by atmosphere annealing. Electrochimica Acta, 2020, 332: 135504

[19] SHEN K, SHENG K, WANG Z T, et al. Cobalt ions doped tungsten oxide nanowires achieved vertically aligned nanostructure with enhanced electrochromic properties. Applied Surface Science, 2020, 501: 144003

[20] ZHOU J L, WEI Y X, LUO G, et al. Electrochromic properties of vertically aligned Ni-doped $\mathrm{WO}_{3}$ nanostructure films and their application in complementary electrochromic devices. Journal of Materials Chemistry C, 2016, 4(8): 1613-1622.

[21] WANG B, MAN W K, YU H Y, et al. Fabrication of Mo-doped $\mathrm{WO}_{3}$ nanorod arrays on FTO substrate with enhanced electrochromic properties. Materials, 2018, 11(9): 1627.

[22] XIE S J, BI Z J, CHEN Y B, et al. Electrodeposited Mo-doped $\mathrm{WO}_{3}$ film with large optical modulation and high areal capacitance toward electrochromic energy-storage applications. Applied Sur- face Science, 2018, 459: 774-781.

[23] WANG W Q, YAO Z J, WANG X L, et al. Niobium doped tungsten oxide mesoporous film with enhanced electrochromic and electrochemical energy storage properties. Journal of Colloid and Interface Science, 2019, 535: 300-307.

[24] ZHAN Y, TAN M R J, CHENG X, et al. Ti-doped $\mathrm{WO}_{3}$ synthesized by a facile wet bath method for improved electrochromism. Journal of Materials Chemistry C, 2017, 5(38): 9995-10000.

[25] SONG Y, ZHANG Z Y, YAN L M, et al. Electrodeposition of Ti-doped hierarchically mesoporous silica microspheres/tungsten oxide nanocrystallines hybrid films and their electrochromic performance. Nanomaterials, 2019, 9(12): 1795.

[26] BATHE S R, PATIL P S. $\mathrm{WO}_{3}$ thin films doped with Ru by facile chemical method with enhanced electrochromic properties for electrochromic window application. Materials Science and Engineering B-Advanced Functional Solid-State Materials, 2020, 257: 114542.

[27] HASANI A, LE Q V, NGUYEN T P, et al. A thorough study on electrochromic properties of metal doped tungsten trioxide film prepared by a facile solution process. Electrochimica Acta, 2018, 283: $1195-1202$.

[28] CHANG J Y, CHEN Y C, WANG C M, et al. Electrochromic properties of lithium-doped tungsten oxide prepared by electron beam evaporation. Coatings, 2019, 9(3): 191.

[29] KIM K H, KOO B R, AHN H J. Effects of Sb-doped $\mathrm{SnO}_{2}-\mathrm{WO}_{3}$ nanocomposite on electrochromic performance. Ceramics International, 2019, 45(13): 15990-15995.

[30] LUO G, SHEN L Y, ZHENG J M, et al. A europium ion doped $\mathrm{WO}_{3}$ film with the bi-functionality of enhanced electrochromic switching and tunable red emission. Journal of Materials Chemistry C, 2017, 5(14): 3488-3494.

[31] SHEN L Y, LUO G, ZHENG J M, et al. Effect of $\mathrm{pH}$ on the electrochromic and photoluminescent properties of Eu doped $\mathrm{WO}_{3}$ film. Electrochimica Acta, 2018, 278: 263-270.

[32] YIN Y, LAN C Y, HU S M, et al. Effect of Gd-doping on electrochromic properties of sputter deposited $\mathrm{WO}_{3}$ films. Journal of Alloys and Compounds, 2018, 739: 623-631.

[33] SHEN L Y, ZHENG J M, XU C Y. Enhanced electrochromic switches and tunable green fluorescence based on terbium ion doped $\mathrm{WO}_{3}$ films. Nanoscale, 2019, 11(47): 23049-23057.

[34] KUNYAPAT T, XU F, NEATE N, et al. Ce-doped bundled ultrafine diameter tungsten oxide nanowires with enhanced electrochromic performance. Nanoscale, 2018, 10(10): 4718-4726.

[35] YAO Y J, ZHAO Q, WEI W, et al. $\mathrm{WO}_{3}$ quantum-dots electrochromism. Nano Energy, 2020, 68: 104350.

[36] XIE Z, ZHANG Q, LIU Q, et al. Enhanced electrochromic performance of 2D grid-structured $\mathrm{WO}_{3}$ thin films. Thin Solid Films, 2018, 653: 188-193.

[37] YUAN G Z, HUA C Z, KHAN S, et al. Improved electrochromic performance of $\mathrm{WO}_{3}$ films with size controlled nanorods. Electrochimica Acta, 2018, 260: 274-280.

[38] ZHANG K, LI N, WANG Y, et al. Bifunctional urchin-like $\mathrm{WO}_{3} @$ PANI electrodes for superior electrochromic behavior and lithium-ion battery. Journal of Materials Science-Materials in Electronics, 2018, 29(17): 14803-14812.

[39] GUO Q F, ZHAO X Q, LI Z Y, et al. A novel solid-state electrochromic supercapacitor with high energy storage capacity and cycle stability based on poly(5-formylindole)/ $/ \mathrm{WO}_{3}$ honeycombed porous nanocomposites. Chemical Engineering Journal, 2020, 384: 123370

[40] BODE H, DEHMELT K, WITTE J. Zur kenntnis der nickelhydroxidelektrode-I. Über das nickel (II)-hydroxidhydrat. 
Electrochimica Acta , 1966, 11: 1079-1087.

[41] PASSERINI S, SCROSATI B. Electrochromism of thin-film nickel-oxide electrodes. Solid State Ionics, 1992, 53: 520-524.

[42] BOUESSAYA I, ROUGIER A, POIZOT P, et al. Electrochromic degradation in nickel oxide thin film: a self-discharge and dissolution phenomenon. Electrochimica Acta, 2005, 50(18): 3737-3745.

[43] DONG D M, WANG W W, ROUGIER A, et al. Life-cycling and uncovering cation-trapping evidence of a monolithic inorganic electrochromic device: glass/ITO/ $\mathrm{WO}_{3} / \mathrm{LiTaO}_{3} / \mathrm{NiO} / \mathrm{ITO}$. Nanoscale, 2018, 10(35): 16521-16530.

[44] AMIRZHANOVA A, KARAKAYA I, UZUNDAL C B, et al. Synthesis and water oxidation electrocatalytic and electrochromic behaviours of mesoporous nickel oxide thin film electrodes. Journal of Materials Chemistry A, 2019, 7(38): 22012-22020.

[45] PAN J B, ZHENG R Z, WANG Y, et al. A high-performance electrochromic device assembled with hexagonal $\mathrm{WO}_{3}$ and $\mathrm{NiO} / \mathrm{PB}$ composite nanosheet electrodes towards energy storage smart window. Solar Energy Materials and Solar Cells, 2020, 207: 110337.

[46] YUE Y F, LI H Z, LI K R, et al. Preparation and properties of $\mathrm{NiO} / \mathrm{PB}$ hybrid electrochromic film. Journal of Inorganic Materials, 2017, 32(9): 949-954.

[47] ZRIKEM K, SONG G, AGHZZAF A A, et al. UV treatment for enhanced electrochromic properties of spin coated $\mathrm{NiO}$ thin films. Superlattices and Microstructures, 2019, 127: 35-42.

[48] SAADEDDIN I, SULEIMAN M, SALMAN H, et al. Optimization of low value electrodeposition parameters of nano-structured $\mathrm{NiO}$ electrochromic thin films. Solid State Ionics, 2019, 343: 115129.

[49] WANG M, THIMONT Y, PRESMANES L, et al. The effect of the oxygen ratio control of DC reactive magnetron sputtering on as-deposited non stoichiometric $\mathrm{NiO}$ thin films. Applied Surface Science, 2017, 419: 795-801.

[50] ZHOU K L, QI Z C, ZHAO B W, et al. The influence of crystallinity on the electrochromic properties and durability of $\mathrm{NiO}$ thin films. Surfaces and Interfaces, 2017, 6: 91-97.

[51] HOU S, GAVRILYUK A I, ZHAO J P, et al. Controllable crystallinity of nickel oxide film with enhanced electrochromic properties. Applied Surface Science, 2018, 451: 104-111.

[52] FIRAT Y E, PEKSOZ A. Efficiency enhancement of electrochromic performance in $\mathrm{NiO}$ thin film via $\mathrm{Cu}$ doping for energysaving potential. Electrochimica Acta, 2019, 295: 645-654.

[53] HE Y, LI T, ZHONG X, et al. Lattice and electronic structure variations in critical lithium doped nickel oxide thin film for superior anode electrochromism. Electrochimica Acta, 2019, 316: 143-151.

[54] LEE S J, LEE T G, NAHM S, et al. Investigation of all-solid-state electrochromic devices with durability enhanced tungsten-doped nickel oxide as a counter electrode. Journal of Alloys and Compounds, 2020, 815: 152399.

[55] DONG D, WANG W, BARNABE A, et al. Enhanced electrochromism in short wavelengths for $\mathrm{NiO}:(\mathrm{Li}, \mathrm{Mg})$ films in full inorganic device ITO/NiO:(Li, Mg)/ $/ \mathrm{Ta}_{2} \mathrm{O}_{5} / \mathrm{WO}_{3} / \mathrm{ITO}$. Electrochimica Acta, 2018, 263: 277-285.

[56] HUANG Q, ZHANG Q, XIAO Y, et al. Improved electrochromic performance of NiO-based thin films by lithium and tantalum co-doping. Journal of Alloys and Compounds, 2018, 747: 416-422.

[57] WU Z S, LI M Y, WANG X Q, et al. Room-temperature fabrication of $\mathrm{NiO}$ films for electrochromic application by electrophoretic deposition (EPD): from single layers to devices. ECS Journal of Solid State Science and Technology, 2019, 8(9): Q171-Q177.

[58] TIAN Y L, LI Z Y, DOU S L, et al. Facile preparation of aligned
$\mathrm{NiO}$ nanotube arrays for electrochromic application. Surface \& Coatings Technology, 2018, 337: 63-67.

[59] REN Y, ZHOU X G, ZHANG H, et al. Preparation of a porous NiO array-patterned film and its enhanced electrochromic performance. Journal of Materials Chemistry C, 2018, 6(18): 4952-4958.

[60] DONG W J, LV Y, ZHANG N, et al. Trifunctional NiO-Ag-NiO electrodes for ITO-free electrochromic supercapacitors. Journal of Materials Chemistry C, 2017, 5(33): 8408-8414.

[61] LIANG H, LI R, LI C, et al. Regulation of carbon content in MOF-derived hierarchical-porous $\mathrm{NiO} @ \mathrm{C}$ films for highperformance electrochromism. Materials Horizons, 2019, 6(3): 571-579.

[62] WANG M Y, BARNABE A, THIMONT Y, et al. Optimized properties of innovative ElectroChromic Device using ITO/Ag/ITO electrodes. Electrochimica Acta, 2019, 301: 200-208.

[63] WANG M Y, LIU Q R, DONG G B, et al. Influence of thickness on the structure, electrical, optical and electrochromic properties of AZO thin films and their inorganic all-solid-state devices. Electrochimica Acta, 2017, 258: 1336-1347.

[64] LIU Q, DONG G, XIAO Y, et al. An all-thin-film inorganic electrochromic device monolithically fabricated on flexible PET/ITO substrate by magnetron sputtering. Materials Letters, 2015, 142: 232-234.

[65] LEE H B, JIN W Y, OVHAL M M, et al. Flexible transparent conducting electrodes based on metal meshes for organic optoelectronic device applications: a review. Journal of Materials Chemistry C, 2019, 7(5): 1087-1110.

[66] CAI G F, CHENG X, LAYANI M, et al. Direct inkjet-patterning of energy efficient flexible electrochromics. Nano Energy, 2018, 49: $147-154$.

[67] CAI G F, DARMAWAN P, CUI M Q, et al. Highly stable transparent conductive silver grid/PEDOT:PSS electrodes for integrated bifunctional flexible electrochromic supercapacitors. Advanced Energy Materials, 2016, 6(4): 1501882.

[68] WEI Y X, CHEN M, LIU W M, et al. Electrochemical investigation of electrochromic devices based on $\mathrm{NiO}$ and $\mathrm{WO}_{3}$ films using different lithium salts electrolytes. Electrochimica Acta, 2017, 247: $107-115$.

[69] YANG X W, CONG S, LI J, et al. An aramid nanofibers-based gel polymer electrolyte with high mechanical and heat endurance for all-solid-state NIR electrochromic devices. Solar Energy Materials and Solar Cells, 2019, 200: 109952.

[70] WOOTTHIKANOKKHAN J, JARUPHAN P, AZARIAN M H, et al. Effects of ethylene-acrylic acid ionomer on thermomechanical and electrochromic properties of electrochromic devices using gelatin-based electrolytes. Journal of Applied Polymer Science, 2020, 137(44): e49362.

[71] XIAO Y, DONG G B, GUO J J, et al. Thickness dependent surface roughness of sputtered $\mathrm{Li}_{2.5} \mathrm{TaO}_{x}$ ion conductor and its effect on electro-optical performance of inorganic monolithic electrochromic device. Solar Energy Materials and Solar Cells, 2018, 179: 319-327.

[72] ZHOU Y L, DIAO X G, DONG G B, et al. Enhanced transmittance modulation of ITO/ $\mathrm{NiO}_{x} / \mathrm{ZrO}_{2}: \mathrm{H} / \mathrm{WO}_{3} / \mathrm{ITO}$ electrochromic devices. Ionics, 2016, 22(1): 25-32.

[73] CHEN X, DOU S L, LI W J, et al. All solid state electrochromic devices based on the LiF electrolyte. Chemical Communications, 2020, 56(37): 5018-5021.

[74] XIAO Y, ZHONG X, GUO J, et al. The role of interface between LiPON solid electrolyte and electrode in inorganic monolithic electrochromic devices. Electrochimica Acta, 2018, 260: 254-263.

[75] XIE L L, ZHAO S W, ZHU Y, et al. High performance and 
excellent stability of all-solid-state electrochromic devices based on a $\mathrm{Li}_{1.85} \mathrm{AlO}_{z}$ ion conducting layer. ACS Sustainable Chemistry \& Engineering, 2019, 7(20): 17390-17396.

[76] DONG D, WANG W, DONG G, et al. Electrochromic properties and performance of $\mathrm{NiO}_{x}$ films and their corresponding all-thinfilm flexible devices preparedby reactive DC magnetron sputtering. Applied Surface Science, 2016, 383: 49-56.

[77] LIU Q, DONG G, XIAO Y, et al. Electrolytes-relevant cyclic durability of nickel oxide thin films as an ion-storage layer in an all-solid-state complementary electrochromic device. Solar Energy Materials and Solar Cells, 2016, 157: 844-852.

[78] WU Z H, DIAO X G, DONG G B. Preparation and Properties of All-solid-state Inorganic Thin Film Glass/ITO/ $/ \mathrm{WO}_{3} / \mathrm{LiNbO}_{3} / \mathrm{NiO}_{x} / \mathrm{ITO}$ Electrochromic Device. Selected Papers of the Photoelectronic Technology Committee Conferences Held November 2015. International Society for Optics and Photonics, 2016, 9796: 979612.

[79] DONG D, WANG W, DONG G, et al. Improved performance of co-sputtered Ni-Ti oxide films for all-solid-state electrochromic devices. RSC Advances, 2016, 6(112): 111148-111160.

[80] ZHANG F, DONG G B, LIU J, et al. Polyvinyl butyral-based gel polymer electrolyte films for solid-state laminated electrochromic devices. Ionics, 2017, 23(7): 1879-1888.

[81] WANG M, DIAO X, DONG G, et al. Optical, electrical, and electrochemical properties of indium tin oxide thin films studied in different layer-structures and their corresponding inorganic all-thin-film solid-state electrochromic devices. Journal of Vacuum Science \& Technology A, 2017, 35(2): 021512.

[82] HUANG Q, DONG G, XIAO Y, et al. Electrochemical studies of silicon nitride electron blocking layer for all-solid-state inorganic electrochromic device. Electrochimica Acta, 2017, 252: 331-337.

[83] ATAK G, COSKUN O D. Annealing effects of $\mathrm{NiO}$ thin films for all-solid-state electrochromic devices. Solid State Ionics, 2017, 305: 43-51.

[84] XIAO Y, DONG G, HUANG Q, et al. Electro-optical performance of inorganic monolithic electrochromic device with a pulsed DC sputtered $\mathrm{Li}_{x} \mathrm{Mg}_{y} \mathrm{~N}$ ion conductor. Journal of Solid State Electrochemistry, 2018, 22(1): 275-283.

[85] WANG W J, GUAN S, LI M, et al. A novel hybrid quasi-solid polymer electrolyte based on porous PVB and modified PEG for electrochromic application. Organic Electronics, 2018, 56: 268-275.

[86] CHE X Q, WU Z H, DONG G B, et al. Properties of all-thin-film glass $/ \mathrm{ITO} / \mathrm{WO}_{3}: \mathrm{H} / \mathrm{Ta}_{2} \mathrm{O}_{5} / \mathrm{NiO}_{x} / \mathrm{ITO}$ electrochromic devices pre- pared by magnetron sputtering. Thin Solid Films, 2018, 662: 6-12.

[87] ZHU Y, XIE L L, CHANG T C, et al. High performance all-solid-state electrochromic device based on $\mathrm{Li}_{x} \mathrm{NiO}_{y}$ layer with gradient Li distribution. Electrochimica Acta, 2019, 317: 10-16.

[88] LIU Q R, DONG G B, CHEN Q Q, et al. Charge-transfer kinetics and cyclic properties of inorganic all-solid-state electrochromic device with remarkably improved optical memory. Solar Energy Materials and Solar Cells, 2018, 174: 545-553.

[89] ATAK G, COSKUN O D. Fabrication of an all solid-state electrochromic device using zirconium dioxide as an ion-conducting layer. Thin Solid Films, 2018, 664: 70-78.

[90] COSKUN O D, ATAK G. The effects of lithiation process on the performance of all-solid-state electrochromic devices. Thin Solid Films, 2018, 662: 13-20.

[91] TANG C J, HE J L, JAING C C, et al. An all-solid-state electrochromic device based on $\mathrm{WO}_{3}-\mathrm{Nb}_{2} \mathrm{O}_{5}$ composite films prepared by fast-alternating bipolar-pulsed reactive magnetron sputtering. Coatings, 2019, 9(1): 9-15.

[92] XIE Z Q, LIU Q Q, ZHANG Q Q, et al. Fast-switching quasi-solid state electrochromic full device based on mesoporous $\mathrm{WO}_{3}$ and $\mathrm{NiO}$ thin films. Solar Energy Materials and Solar Cells, 2019, 200: 110017 .

[93] LIU L, DU K, HE Z, et al. High-temperature adaptive and robust ultra-thin inorganic all-solid-state smart electrochromic energy storage devices. Nano Energy, 2019, 62: 46-54.

[94] PAN L J, HAN Q N, DONG Z L, et al. Reactively sputtered $\mathrm{WO}_{3}$ thin films for the application in all thin film electrochromic devices. Electrochimica Acta, 2019, 328: 135107.

[95] LI W J, ZHANG X, CHEN X, et al. Preparation and performance of fast-response $\mathrm{ITO} / \mathrm{Li}-\mathrm{NiO} / \mathrm{Li}-\mathrm{WO}_{3} / \mathrm{ITO}$ all-solid-state electrochromic devices by evaporation method. Materials Letters, 2020, 265: 127464 .

[96] KADAM A V. Electrochromic properties of ITO/ $\mathrm{WO}_{3} / \mathrm{LiClO}_{4}{ }^{-}$ PC-PMMA-ACN/NiO/ITO framework. Materials Today-Proceedings, 2020, 23: 352-358.

[97] WANG C P, DONG G B, ZHAO Y Y, et al. Enhanced electrochromic performance on anodic nickel oxide inorganic device via lithium and aluminum co-doping. Journal of Alloys and Compounds, 2020, 821: 153365.

[98] DING Y, DONG G, ZHOU Y, et al. Improved performance of all-thin-film electrochromic devices with two $\mathrm{ZrO}_{2}$ protective layers. Ionics, 2018, 24(8): 2427-2434. 